\section{P-34 INTRODUCING SCHOOL CHILDREN TO HOSPICE CARE - BENEFITS TO PATIENTS AND PUPILS}

Liz Morgan. Nottinghamshire Hospice, Nottingham, UK

10.1136/bmjspcare-2019-HUKNC.58

Nottinghamshire Hospice is passionate about providing hospice care to all our communities. Previously primary school groups have come in to sing Christmas carols to patients in day therapy and in the Summer two local schools came for picnics with patients. These picnics involved more interaction between pupils and patients than Christmas singing had provided. Patients and pupils played games together, shared stories about their 'teddies' and toured the hospice gardens.

It was concluded that this was a great starting base to take schools work further and to develop an interactive teaching programme which benefits patients, pupils, schools, parents and Nottinghamshire Hospice.

The hospice therefore invited a class of children into the hospice for four afternoons to work on a 1:1 basis with patients with the aims of:

- Raising awareness in the community about the hospice's work;

- Address myths and reduce anxieties around loss and bereavement;

- Create healthier attitudes towards death, dying and aging;

- For patients and pupils to have some fun and laughter.

Activities involved

- Patients and pupils talking and getting to know each other's interests, what's special to them and what they enjoy about the school and hospice. This was evidenced in creating poems which were read out to patients and parents;

- Pupils saw all aspects of hospice life including HR, finance and maintenance;

- Reading and discussing 'Paper Dolls' story together which talks about memories and having a workbook and craft around this story.

Feedback was positive from pupils, patients, parents, school staff and hospice staff. The children learnt a lot about 'their patient', this was reflected in the poems they wrote together.

School staff and parents were reflective on the warm and happy atmosphere that the hospice provided and how the children had interacted with people much older than themselves and hospice staff enjoyed sharing their knowledge.

\section{P-35 EDUCATIONAL OUTREACH - EARLY EDUCATION OF YOUNG MINDS ABOUT MODERN-DAY HOSPICE CARE}

Susannah Parry. Garden House Hospice Care, Letchworth, UK

\subsection{6/bmjspcare-2019-HUKNC.59}

Background In September 2018, a Community Engagement Schools and Colleges Co-ordinator was recruited to set up and deliver a new educational outreach service. With a background in teaching, the Co-ordinator recognised the value and potential of linking the work of the hospice to National Curriculum objectives that would support and enrich learning inside and out of the classroom.

Aims To strengthen collaborative working with schools, colleges and youth organisations within the catchment area; to promote awareness of the work of the hospice, the hospice movement in general and palliative and end of life care.

Methods October 2018: research began into schools and colleges work currently on offer by other hospices. Professional links made. November 2018: marketing materials developed. Co-ordinator searched National Curriculum documents and Schemes of Work to see where educational links could be made. December 2018: educational pack developed for primary schools to include curriculum-based assemblies, lessons or group talks. January-March 2019: in-house schools visits and projects investigated and developed to encourage young people to visit the hospice.

Results Between January-July 2019, the Co-ordinator attended over 20 local schools for assemblies and talks. Awareness is growing for the new service and future bookings are being made for the 2019/20 academic year. From March to June 2019 three pilot in-house schools projects took place where children worked with day services patients. Initial evaluations from patients, teachers, children and parents has been extremely positive, with patients asking to sign up again.

Conclusions Through our educational outreach, we are not only educating our next generation on what modern day hospice care is, but it has the potential to dispel myths and change wider public perception. Based on initial positive feedback, next steps are to embed the Primary service and extend out to Secondary schools through talks, enterprise initiatives or community projects.

\section{P-36 WHY EVERY HOSPICE SHOULD HAVE A SCHOOLS PROJECT}

Marcelle Palmer. St Barnabas House, Worthing, UK

10.1136/bmjspcare-2019-HUKNC.60

Background The National Council for Palliative Care (2015) highlighted that there are considerable social taboos when discussing death and dying, yet it is well documented that honest end-of-life conversations can enhance capability to live and die well (Department of Health, 2008).

In line with national strategies to increase public awareness of hospices' work and after exploring other approaches to this project, the hospice was keen to establish and evaluate the benefits of running a course for school children, patients and hospice.

Aims

- Engage, create links and inform our community about the hospice's work;

- Offer an opportunity for patients to engage in activities of sharing their knowledge and life-stories with children and wider community;

- Provide safe environment for children to explore aspects of ill-health, death, dying and the 'circle of life';

- Impact evaluation of all participants.

Methods January 2016 to May 2016: literature review, networked with other hospices, internal consultations, service planning; June 2016 to August 2016 - school recruited, year-5 students and patients to participate in pilot project; September 2016 to March 2017 - ran pilot project and evaluation; September 2017 to present - eleven courses/academic year as established service; participants counted. Self-assessment/questionnaire evaluation by all participants. Social media activity monitored. 
Results

- Initial pilot - one school, 32 children, seven patients, four carers, six school staff;

- 2017-2018 - eight schools, 126 children, ten patients, 73 family members, 22 teaching staff, three carers (assemblies 578 attendees);

- 2018-2019 (so far) - ten schools, 116 children, 13 patients, 80 family members, 23 teaching staff, four carers, (assemblies 829 attendees). Three hospices visited and now using Schools Project to inform their own model.

Conclusion The evaluation of the schools project shows a positive impact on children, patients and wider community. We have learnt from those involved that it has reduced taboos around death and dying and has a positive effect on patients. In-depth study being explored.

\section{P-37 NORMALISING DEATH AND DYING: AN INTRODUCTION TO HOSPICE CARE FOR CHILDREN}

Claire Lane, Rachel Morris, Lorna Richardson. Marie Curie Hospice, Liverpool, UK

\subsection{6/bmjspcare-2019-HUKNC.61}

Background Death and dying are still taboo subjects within British society, and this is particularly true when discussing end-of-life with children (Christ \& Christ, 2006; Fearnley \& Boland, 2019; McManus \& Paul, 2019; Paul, 2016). There is little opportunity for children to gain understanding of palliative care, especially those whose families have not experienced terminal illness (Lawrance \& Mitchell, 2018; Paul, Cree \& Murray, 2016). A project was designed to link a Liverpoolbased hospice and a local secondary school by inviting pupils to spend time with staff and patients in the Day Therapy Unit.

Aims To raise students' awareness of palliative care and the role of the hospice within the community.

Methods Contact was made between the hospice and a local secondary school to arrange a pilot project. The school identified six students to participate based on the students' resilience and maturity. These students attended a session with hospice staff to gain some understanding of palliative care and ask questions within a supportive environment.

The students were invited to the Day Therapy Unit weekly to engage with hospice staff and patients in a range of activities. After six weeks the students were invited to run an activity for the patients.

Results Feedback received was overwhelmingly positive. The students enjoyed spending time in the hospice, with one significantly interested in volunteering on a regular basis. The patients and staff were always happy to see the students, engaging them in conversation and encouraging their participation.

Conclusions In the future we plan to engage more students in projects and aim to encourage these students to present their experiences to their peers. We will also look to measure learning objectives both before and after the students' visits.

The pilot project has shown that it is possible for children to experience our hospice in a safe and enjoyable manner, therefore gaining greater understanding around palliative care and the role of a hospice.

\section{P-38 BUZZING ABOUT COMPASSIONATE COMMUNITIES}

Debra Lawson, Helen Birch, Rachel Kennedy, Kate Tipton-Thomas. Queenscourt Hospice, Southport, UK

\subsection{6/bmjspcare-2019-HUKNC.62}

Background Queenie's Roadshow is an engagement project targeted at local schools and nurseries. Pupils receive a free presentation from the hospice's Community Fundraiser and our mascot, Queenie. The presentation gives pupils the opportunity to learn about the invaluable work that is carried out by the hospice and their wider services.

In July, schools will hold a fundraising activity or event during their Sports Day. This is the first year in which the Roadshow has run, and whilst the focus is on engaging with local schools and nurseries to increase awareness of hospice work, dying and bereavement, it is estimated that there will be an income of approximately $£ 1,000$.

Aim The aim is engagement with local schools and nurseries to develop long-lasting relationships. This will help build Compassionate Communities and increase fundraising activities.

Methods Social media marketing. This reached 1,274 people, 75 of which engaged with the Facebook post. Traditional marketing via written request (to those who had consented) to schools and nurseries did not result in any engagement.

Results Results are anecdotal at this point as the campaign is ongoing. Children have been curious and excited to engage and have conversations. This is beginning to increase awareness. To this point, six schools/nurseries are signed up to the campaign.

Conclusion We believe that by utilising our mascot effectively we will not only develop long-lasting relationships with our local schools, but we will also raise awareness and knowledge of our hospice in a way that enables conversations about dying and bereavement with young people. We can use these experiences as building blocks within the development of Compassionate Communities as well as benefitting from fundraising activity by each school/nursery.

\section{P-39 THE EVOLUTION OF AN IDEA: ESTABLISHING THE LOROS YOUTH AMBASSADOR PROGRAMME}

Abigail Wattam. LOROS, Leicester, UK

\subsection{6/bmjspcare-2019-HUKNC.63}

Background Providing opportunities to young people allows them to develop skills and experience for work, education and adulthood (NHS England, 2019; Kirkman, Sanders, Emanuel, \& Larkin, 2016). Aligned with our community development work, LOROS continues to develop its links with younger volunteers and has supported the appointment of a dedicated Youth Engagement Officer (LOROS Hospice three year strategic plan, 2019.) The LOROS Youth Ambassador Programme is striving to connect the hospice to the youth communities of Leicester, Leicestershire and Rutland.

Aims The programme aims to consolidate, expand and celebrate young people's visibility in raising awareness of a charitable organisation and developing leadership, resilience, confidence and enthusiasm (Naidoo, 2001; Great British Entrepreneur Awards, 2018).

Methods June to August 2018 - research models of existing Youth Ambassador programmes, with examples found at 